Document downloaded from:

http://hdl.handle.net/10251/103604

This paper must be cited as:

Martínez-Haya, R.; Gomis, J.; Arqués Sanz, A.; Marín García, ML.; Amat Payá, AM.; Miranda Alonso, MÁ. (2017). Time-resolved kinetic assessment of the role of singlet and triplet excited states in the photocatalytic treatment of pollutants at different concentrations. Applied Catalysis B Environmental. 203:381-388. doi:10.1016/j.apcatb.2016.10.042

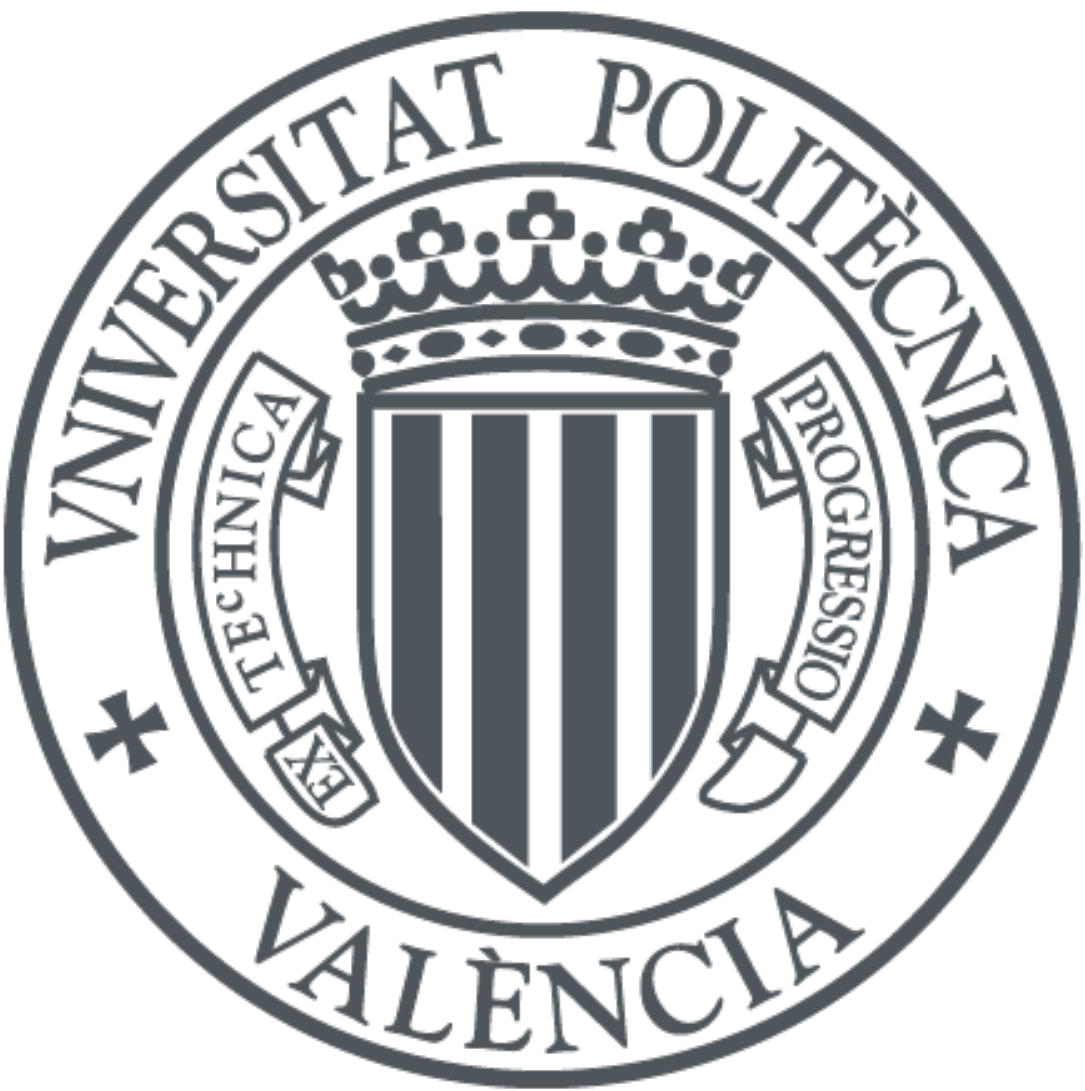

The final publication is available at

http://dx.doi.org/10.1016/j.apcatb.2016.10.042

Copyright Elsevier

Additional Information 
4

\title{
Time-resolved kinetic assessment of the role of singlet and triplet excited states in the photocatalytic treatment of pollutants at different concentrations
}

\author{
J. Gomis, ${ }^{a}$ R. Martinez-Haya, ${ }^{b}$ A. Arques, ${ }^{a,}{ }^{*}$ M. L. Marin,,${ }^{\text {b* }}$ A. M. Amat, ${ }^{\text {a }}$ and M.A. \\ Miranda ${ }^{b}$ \\ ${ }^{a}$ Grupo de Procesos de Oxidación Avanzada, Departamento de Ingeniería Textil y \\ Papelera, Universitat Politècnica de València, Campus de Alcoy, Alcoy, Spain \\ bInstituto de Tecnología Química, Universitat Politècnica de València-Consejo Superior \\ de Investigaciones Científicas, Avenida de los Naranjos s/n, 46022 Valencia, Spain. \\ *Corresponding author \\ E-mail addresses: aarques@txp.upv.es; marmarin@qim.upv.es
}


2 A kinetic-based rationale to assess the role of each excited species in thermodynamically

3 favored photocatalytic processes at different pollutant concentrations, has been developed

4 and illustrated with new experimental data. Specifically, 2,4,6-triphenylthiapyrylium

$5 \quad\left(\mathrm{TPTP}^{+}\right)$salt has been chosen as a representative organic compound capable to act as

6 photocatalyst, and the possible involvement of its excited states in the photodegradation

7 of pollutants commonly found in aqueous ecosystems has been investigated using five

8 chemicals, namely acetaminophen, acetamiprid, caffeine, clofibric acid and

9 carbamazepine. First, steady-state photolysis has been carried out under simulated solar

10 irradiation in the presence of $\mathrm{TPTP}^{+}$, and second, photophysical measurements

11 (fluorescence and laser flash photolysis) have been performed in order to obtain reliable

12 fast kinetic data. Thermodynamic considerations allow ruling out energy transfer

13 processes, while the kinetic results are in good agreement with an electron transfer to the

14 triplet excited state of $\mathrm{TPTP}^{+}$. Hence, the higher the intersystem crossing quantum yield

15 the better. Although quenching of the singlet excited state is also observed, the

16 contribution of this reactive species is only minor, due to its shorter lifetime. In general,

17 the efficiency of a photocatalyst should be enhanced at higher pollutant concentrations,

18 at which the intrinsic decay of the triplet excited state is minimized. 


\section{Keywords}

2 Electron transfer; laser flash photolysis; photo-redox catalysis; singlet excited state;

3 triplet excited state

\section{1. Introduction}

6 Photochemical processes are among the most important abiotic pathways for the removal

7 of pollutants from aqueous ecosystems.[1,2] These processes can occur upon direct

8 absorption of light by the pollutant (direct photolysis), or indirectly through the formation

9 of highly reactive species that react, in turn, with the pollutant (photocatalyzed

10 degradation). Several species can mediate the indirect mechanisms, among them hydroxyl

11 radicals, singlet oxygen, superoxide anion, inorganic radicals (chloride, sulfate,

12 carbonate), organic radicals (carboxyl, peracyl) or excited states of dissolved or suspended organic substances.[3-7]

An overall analysis of photocatalyzed-redox processes should consider two complementary aspects: the thermodynamic and the kinetic viability of all the competing pathways. More specifically, first thermodynamic estimations based on the redox potentials of the involved species could help to discard those pathways that result highly endergonic. Second, a fast kinetic analysis of the thermodynamically allowed key steps, based on the lifetime of the involved transient species, is necessary to elucidate whether the processes are competitive at that time scale. In this context, a photophysical study seams meaningful, as it allows direct monitoring of reactive species, providing timeresolved data in the micro or nanosecond scale.[8] An overall analysis of the obtained photophysical data would help to elucidate the role of each competitive photoactive species. One more parameter that seems meaningful to evaluate is the efficiency of the photocatalyst versus pollutant concentration. In fact, it is generally accepted that below a critical concentration, pollutants behave as recalcitrant. 
1 Such a complete analysis requires a proxy that offers the possibility of monitoring the

2 derived-excited species. For this purpose, a 2,4,6-triphenylthiapyrylium $\left(\mathrm{TPTP}^{+}\right)$salt (see

3 Fig. 1 left for the chemical structure) could be a good candidate to study the interaction

4 between excited organic species and pollutants. As regards the thermodynamic aspect,

$5 \mathrm{TPTP}^{+}$is an extremely good oxidant from its singlet and triplet excited states with

$6 \mathrm{E}^{*}\left(\mathrm{TPTP}^{+} / \mathrm{TPTP}\right)$ ca. 2.5 or $2.0 \mathrm{~V}$ vs SCE, respectively. Besides, it is able to absorb UV-

7 visible light (Fig. 1 right) and displays appropriate photophysical parameters (Fig. 1

8 middle): it exhibits a low fluorescence quantum yield $\left(\Phi_{\mathrm{F}}\right)$ of 0.06 , but a high intersystem

9 crossing quantum yield $\left(\Phi_{\text {ISC }}\right)$ of 0.94 ; it does not sensitize formation of ${ }^{1} \mathrm{O}_{2}$ nor superoxide anion, and its singlet $\left(\tau_{\mathrm{S}}\right)$ and triplet lifetimes $\left(\tau_{\mathrm{T}}\right)$ are of $4.4 \mathrm{~ns}$ and $4.4 \mu \mathrm{s}$, respectively.[8, 9] Despite its high intersystem crossing quantum yield, $\mathrm{TPTP}^{+}$has already demonstrated to achieve oxidative photodegradation of pollutants, through its singlet or/and triplet excited states.[10,11]<smiles>c1ccc(-c2cc(-c3ccccc3)[o+]c(-c3ccccc3)c2)cc1</smiles>

TPTP $^{+}$

\section{Photophysical data}

$$
\begin{gathered}
\Phi_{\mathrm{F}}=0.06 \\
\Phi_{\mathrm{ISC}}=0.94 \\
\tau_{\mathrm{S}}=4.4 \times 10^{-9} \mathrm{~s} \\
\tau_{\mathrm{T}}=4.4 \times 10^{-6} \mathrm{~s} \\
\mathrm{E}_{\mathrm{S}}=66 \mathrm{kcal} \mathrm{mol}^{-1} \\
\mathrm{E}_{\mathrm{T}}=53 \mathrm{kcal} \mathrm{mol}^{-1}
\end{gathered}
$$

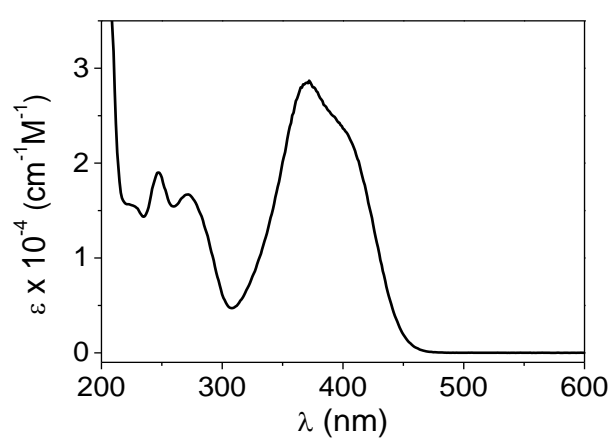

Fig. 1. Chemical structure of 2,4,6-triphenylthiapyrylium $\left(\mathrm{TPTP}^{+}\right)$salt together with its main photophysical parameters and its UV-visible absorption spectrum.

With this background, the main goal of the present paper is to provide a kinetic-based rationale to assess the role of each excited species in a photocatalytic process at different pollutant concentrations. For this purpose, new experimental data are provided and used to illustrate the concept. Specifically, $\mathrm{TPTP}^{+}$has been chosen as a representative organic 
1 compound capable to act as photocatalyst, and the possible involvement of its excited

2 states in the photodegradation of pollutants commonly found in aqueous ecosystems has

3 been investigated. In this work, five chemicals have been selected for the study, namely

4 acetaminophen (ACF), acetamiprid (ACP), caffeine (CAF), clofibric acid (CLOF) and

5 carbamazepine (CBZ) (Fig. 2). First, steady-state photolysis has been carried out under

6 simulated solar irradiation in the presence of $\mathrm{TPTP}^{+}$; second, photophysical

7 measurements (fluorescence and laser flash photolysis) have been performed in order to

8 obtain reliable fast kinetic data; and third, the role of pollutant concentration on the

9 relative contribution of the different excited states to the overall photocatalytic process

10 has been established.
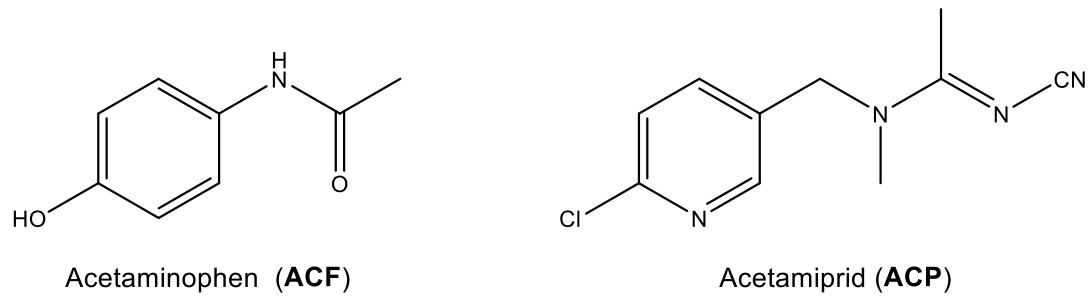<smiles>Cn1c(=O)c2c(ncn2C)n(C)c1=O</smiles>

Caffeine (CAF)<smiles>CC(C)(Oc1ccc(Cl)cc1)C(=O)O</smiles>

Clofibric acid (CLOF)

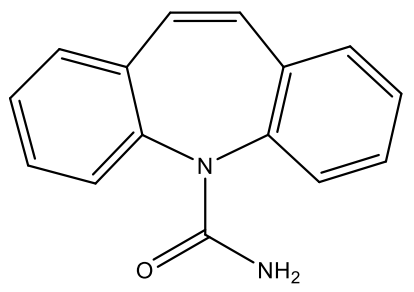

Carbamazepine (CBZ)

Fig. 2. Chemical structures of the selected pollutants.

\section{Experimental}

\subsection{Solar simulated reactions}

Samples were irradiated by means of a solar simulator (Oriel Instruments, Model 81160) 
$2 \mathrm{mg} \mathrm{L}{ }^{-1}$ each) and $\mathrm{TPTP}^{+}\left(10 \mathrm{mg} \mathrm{L}^{-1}\right)$ was introduced in an open Pyrex glass vessel, the

$3 \mathrm{pH}$ was adjusted to 3 by dropwise addition of sulfuric acid, and then irradiated. Magnetic

4 stirring was kept all along the reaction time, and water was added periodically to

5 compensate for the evaporation loss.

6 Aliquots were taken from the reaction mixture, filtered through polypropylene $(0.45 \mu \mathrm{m})$

7 and then injected into a liquid chromatograph (Perkin Elmer model Flexar UPLC FX-10)

8 equipped with a UV-vis detector.

\subsection{Photophysical instrumentation}

Absorption spectra (UV/Vis) were performed on a Shimadzu UV-2101PC spectrometer. Steady-state fluorescence and time-resolved fluorescence experiments were performed in a FS900 fluorometer and a FL900 setup, respectively (Edinburgh Instruments). Lifetime measurements were based on single-photon-counting using a $1.5 \mathrm{~ns}$ pulse width hydrogen flash-lamp as excitation source. The kinetic traces were fitted by monoexponential decay functions using a deconvolution procedure to separate them from the lamp pulse profile. Laser flash photolysis (LFP) experiments were carried out with a pulsed Nd: YAG SL404G-10 Spectron Laser Systems at the excitation wavelength of $355 \mathrm{~nm}$. The energy of the single pulses ( 10 ns duration) was lower than $15 \mathrm{~mJ}$ pulse $^{-1}$. The laser flash photolysis system consisted of the pulsed laser, a pulsed Lo255 Oriel Xenon lamp, a 77200 Oriel monochromator, an Oriel photomultiplier tube (PMT) housing, a 70705 PMT power supply and a TDS-640A Tektronix oscilloscope.

\subsection{Photophysical experiments}

Quartz cells of $1 \mathrm{~cm}$ optical path length were employed for all photophysical measurements, which were run at room temperature. 
1 For the steady-state and time-resolved fluorescence experiments, increasing 2 concentrations of pollutants (up to $7 \times 10^{-3} \mathrm{M}$ in $\mathrm{CH}_{3} \mathrm{CN}$ ) were added to deaerated 3 acetonitrile solutions of $\mathrm{TPTP}^{+}$with absorbance at the excitation wavelength $(400 \mathrm{~nm})$

4 lower than 0.1 . For the laser flash photolysis experiments, increasing amounts of pollutant

5 (up to $7 \times 10^{-5} \mathrm{M}$ ) were added to deaerated acetonitrile solutions of $\operatorname{TPTP}^{+}\left(7 \times 10^{-5} \mathrm{M}\right)$.

6 Job's plot experiments were carried out to investigate the stoichiometry of the complex

$7 \quad\left(\mathrm{TPTP}^{\delta+}--\mathrm{ACP}^{\delta^{\prime}+}\right)$. The absorbance changes were measured at $404 \mathrm{~nm}$ and plotted against

8 the $\mathrm{ACP}$ molecular fraction, keeping the total concentration of $\mathrm{ACP}$ and $\mathrm{TPTP}^{+}$at the

9 constant value of $1 \times 10^{-5} \mathrm{M}$.

$10 \quad 3$. Results and discussion

$11 \quad 3.1$ Solar simulated photodegradation of the pollutants

12 It is known that $\mathrm{TPTP}^{+}$is an extremely good oxidant from its singlet and triplet excited states with $\mathrm{E}^{*}\left(\mathrm{TPTP}^{+} / \mathrm{TPTP} \cdot\right)$ ca. 2.5 or $2.0 \mathrm{~V}$ vs SCE, respectively.[9] Thus, on the basis of the reported redox data for the pollutants[12-15] the photooxidation processes are thermodynamically favoured in all cases.

Therefore, an aqueous solution containing the five selected pollutants was irradiated with a solar simulator in the presence of $\mathrm{TPTP}^{+}$. The $\mathrm{pH}$ of the medium was adjusted to 3 in order to ensure the photostability of this photocatalyst.[16] Fig. 3 shows plots of the relative concentration of each pollutant vs. irradiation time: CLOF and ACF showed the highest photodegradation rates, followed by $\mathrm{CBZ}$ and $\mathrm{CAF}$, while removal of ACP was negligible under the studied experimental conditions. However, quantitative differences were observed among the selected pollutants: in fact, CLOF was completely removed after only $10 \mathrm{~min}$ of irradiation, while $c a .60$ min were required in the case of ACF. On the other hand, CAF and CBZ were not completely removed within the irradiation time, but percentages of removal after $180 \mathrm{~min}$ were $c a .50 \%$. 
1 Control experiments performed by direct photolysis (in the absence of $\mathrm{TPTP}^{+}$) showed

2 almost no reaction apart from CLOF that suffered direct photodegradation but to a much

3 lesser extent. Thus, the photocatalytic degradation produced complete abatement of

4 CLOF in $15 \mathrm{~min}$ while direct photolysis needed $180 \mathrm{~min}$ to provoke $80 \%$ removal (see

5 Fig. S2).

6

7 Fig. 3. Plot of the relative concentration of ACF ( $\bullet), \operatorname{ACP}(\bullet), \operatorname{CAF}(\times), \operatorname{CLOF}(\bullet)$ and

$8 \mathrm{CBZ}(\boldsymbol{\Delta})$ at $\mathrm{C}_{0}=5 \mathrm{mg} \mathrm{L}^{-1}$ and $\mathrm{pH}=3$, vs. solar simulated irradiation time, in the

9 presence of $10 \mathrm{mg} \mathrm{L}^{-1}$ of $\mathrm{TPTP}^{+}$.

17 pollutant at different concentrations.

\subsection{Photophysical studies}

$\mathrm{TPTP}^{+}$is known to act as photocatalyst via electron transfer from its singlet or triplet excited states. In fact, examples of photodegradation from the singlet, triplet or even formation of photoactive ground-state complexes can be found for (thia)pyrylium salts.[10, 11, 17-19] Hence, participation of every potential species in the photodegradation has to be determined in each particular case. Thus, systematic photophysical studies were undertaken and the combined results analyzed for each

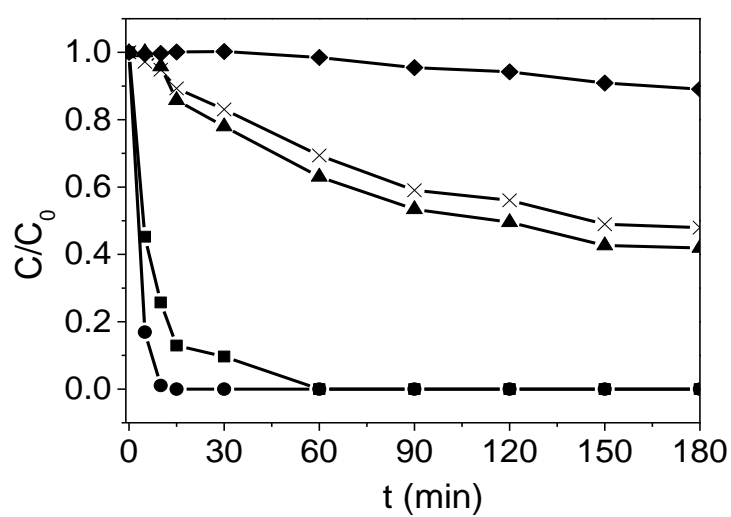

\subsubsection{Fluorescence quenching studies}


1 The potential participation of the singlet excited state of $\mathrm{TPTP}^{+}$was investigated by

2 means of steady-state and time-resolved experiments. In fact, a decrease in the emission

3 intensity and singlet lifetime of ${ }^{1}\left(\mathrm{TPTP}^{+}\right)^{*}$ in deaerated acetonitrile was observed in all

4 cases upon addition of increasing concentration of every pollutant (Fig. 4). The

5 corresponding quenching rate constants were determined applying the Stern-Volmer

6 relationship, between $1 / \tau$ and pollutant concentration. The obtained values (Table 1)

7 confirmed the dynamic involvement of the singlet excited state in all cases, with values

8 close to the diffusion limit.[20]
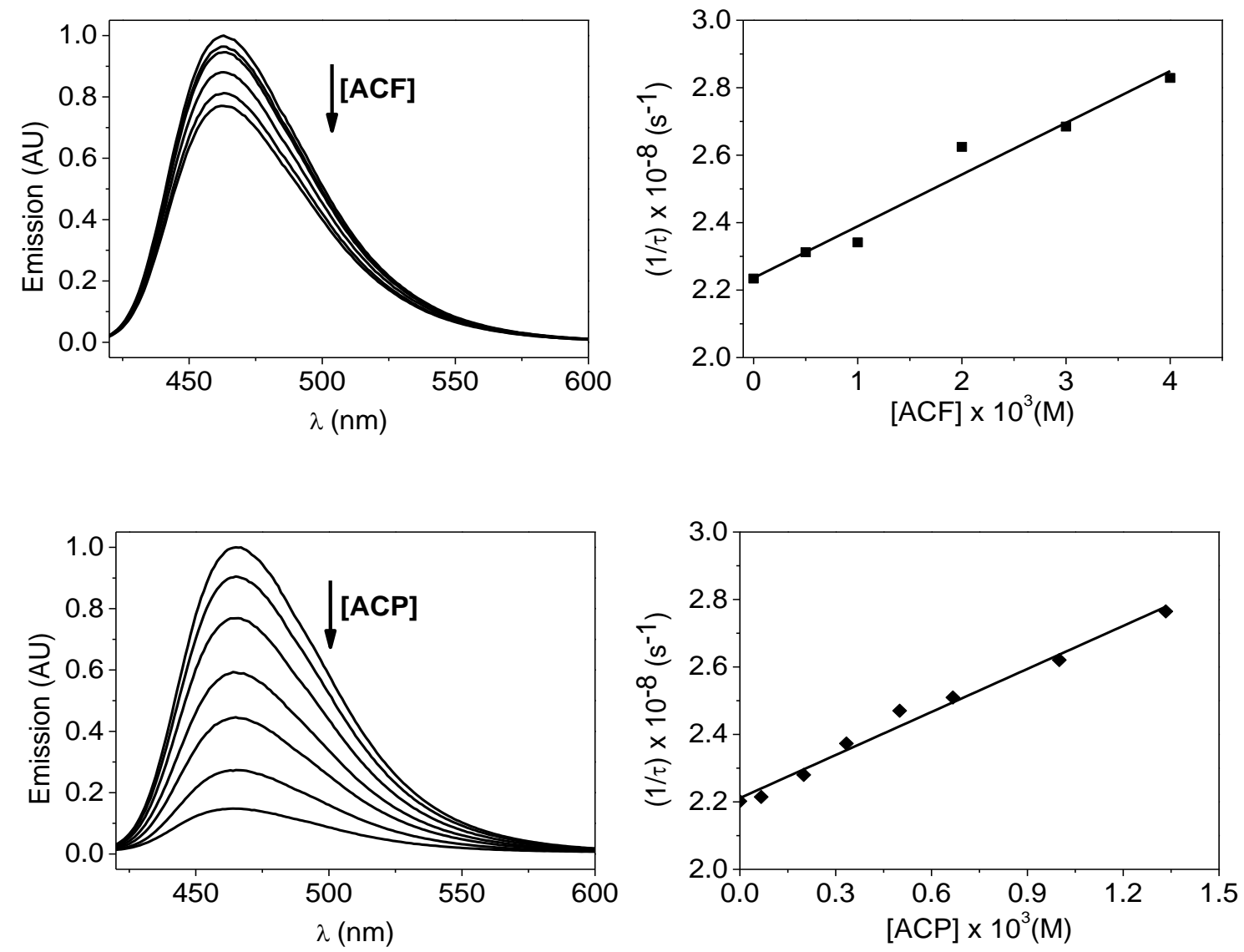

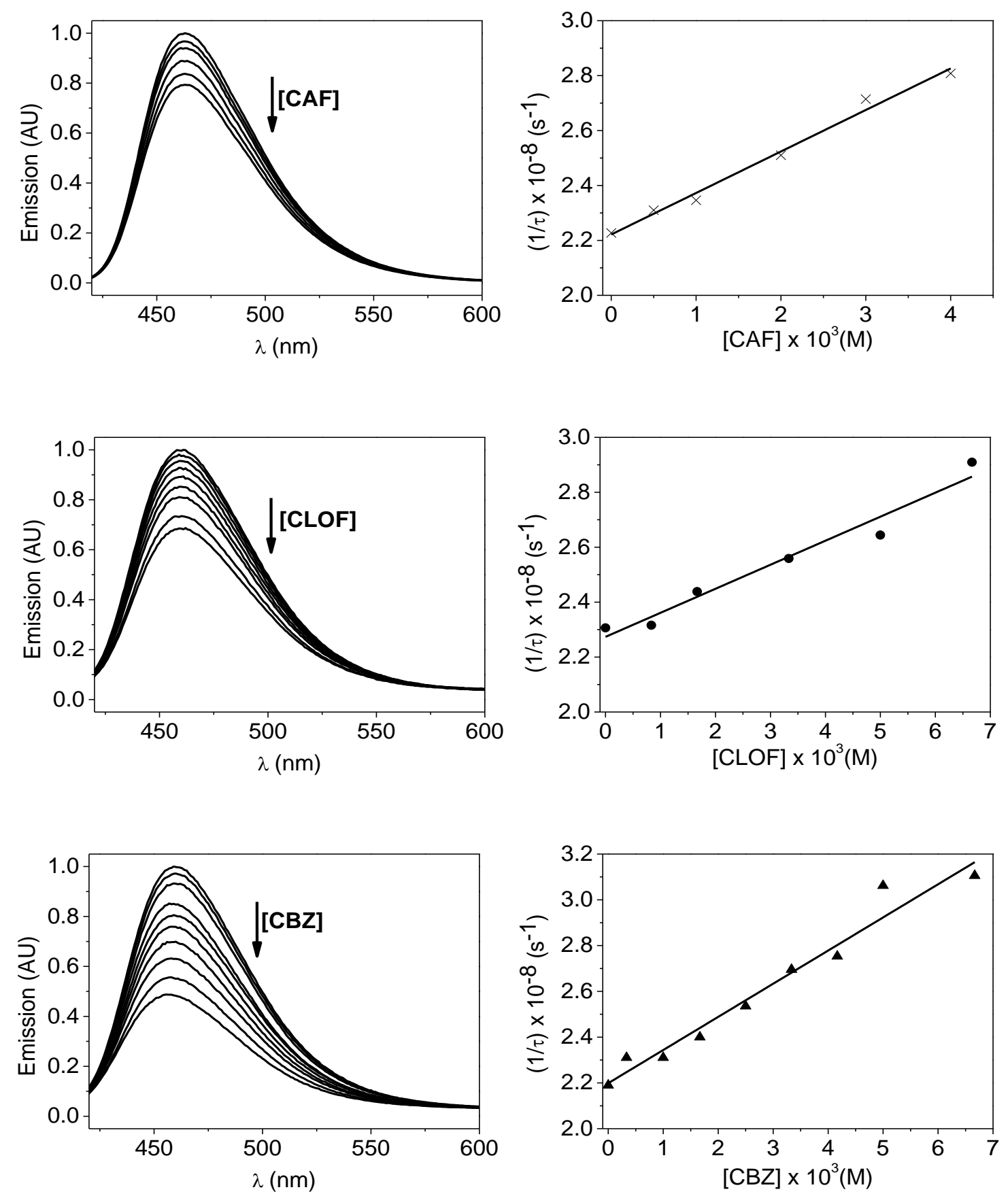

1 Fig. 4. Left column: Steady-state ${ }^{1}\left(\mathrm{TPTP}^{+}\right)^{*}$ fluorescence quenchings; Right column:

2 Stern-Volmer plots obtained from time-resolved experiments; all upon increasing 3 pollutant concentration (up to $\left.7 \times 10^{-3} \mathrm{M}\right)$ in $\mathrm{CH}_{3} \mathrm{CN}\left(\lambda_{\mathrm{exc}}=400 \mathrm{~nm}\right)$.

4 Moreover, it is worth to note that in the case of ACP, when the steady-state emission of

$5{ }^{1}\left(\mathrm{TPTP}^{+}\right)^{*}$ was recorded upon increasing $[\mathrm{ACP}]$, the Stern-Volmer relationship revealed

6 a different behavior (see Supporting Information), clearly deviated from a linear one, and

7 pointing to the formation of a non-emissive ground state complex. The stoichiometry of 
1 the purported complex between $\mathrm{TPTP}^{+}$and $\mathrm{ACP}\left(\mathrm{TPTP}^{\delta+}--\mathrm{ACP}^{\delta^{\prime}+}\right)$ was determined from

2 a Job's plot experiment, $[21,22]$ and subsequent $\mathrm{K}$ value determination was achieved on

3 the basis of the Benesi-Hildebrand relationship ( $\left.\mathrm{K}=503 \mathrm{M}^{-1}\right)$ (see Supplementary

4 Material).[23, 24] Formation of ground-state complexes can have a huge influence on the

5 photocatalytic degradation of a contaminant, since pre-association could result in an

6 "intramolecular-like" reaction proceeding at much higher rate (not-controlled by

7 diffusion) and therefore offering a much more competitive degradation pathway.

\section{$8 \quad 3.2 .2$. Transient absorption spectroscopy}

9 The involvement of the triplet excited state of $\mathrm{TPTP}^{+}$was investigated on the basis of laser flash photolysis (LFP) experiments. Thus, deaerated acetonitrile solutions of TPTP ${ }^{+}$ were submitted to laser flash excitation $(355 \mathrm{~nm})$ and its triplet lifetime was monitored at $620 \mathrm{~nm}$. A decrease in the lifetime was clearly observed in all cases (Fig. 5). The corresponding quenching constants, determined from the Stern-Volmer linear relationships, are shown in Table 1.

Table 1. Rate constant values $\left(k_{q S}\right.$ and $\left.k_{q T}\right)$ for the quenching of ${ }^{1}\left(\mathrm{TPTP}^{+}\right)^{*}$ and ${ }^{3}\left(\mathrm{TPTP}^{+}\right)^{*}$ by the pollutants determined from time-resolved fluorescence quenching and laser flash photolysis experiments.

\begin{tabular}{|l|c|c|}
\hline \multirow{2}{*}{ POLLUTANT } & $k_{q S} \times \mathbf{1 0}^{-\mathbf{- 1 0}}\left(\mathbf{M}^{-\mathbf{1}} \mathbf{s}^{-\mathbf{1}}\right)$ & $k_{q T} \times \mathbf{1 0}^{-\mathbf{8}}\left(\mathbf{M}^{-\mathbf{1}} \mathbf{s}^{-\mathbf{1}}\right)$ \\
\cline { 2 - 3 } & $\mathbf{1}^{\mathbf{1}}\left(\mathbf{T P T P}^{+}\right)^{*}$ & ${ }^{\mathbf{3}}\left(\mathbf{T P T P}^{+}\right)^{*}$ \\
\hline ACF & 1.5 & 110 \\
\hline ACP & 4.4 & 6.8 \\
\hline CAF & 1.5 & 98 \\
\hline CLOF & 0.8 & 84 \\
\hline CBZ & 1.5 & 81 \\
\hline
\end{tabular}



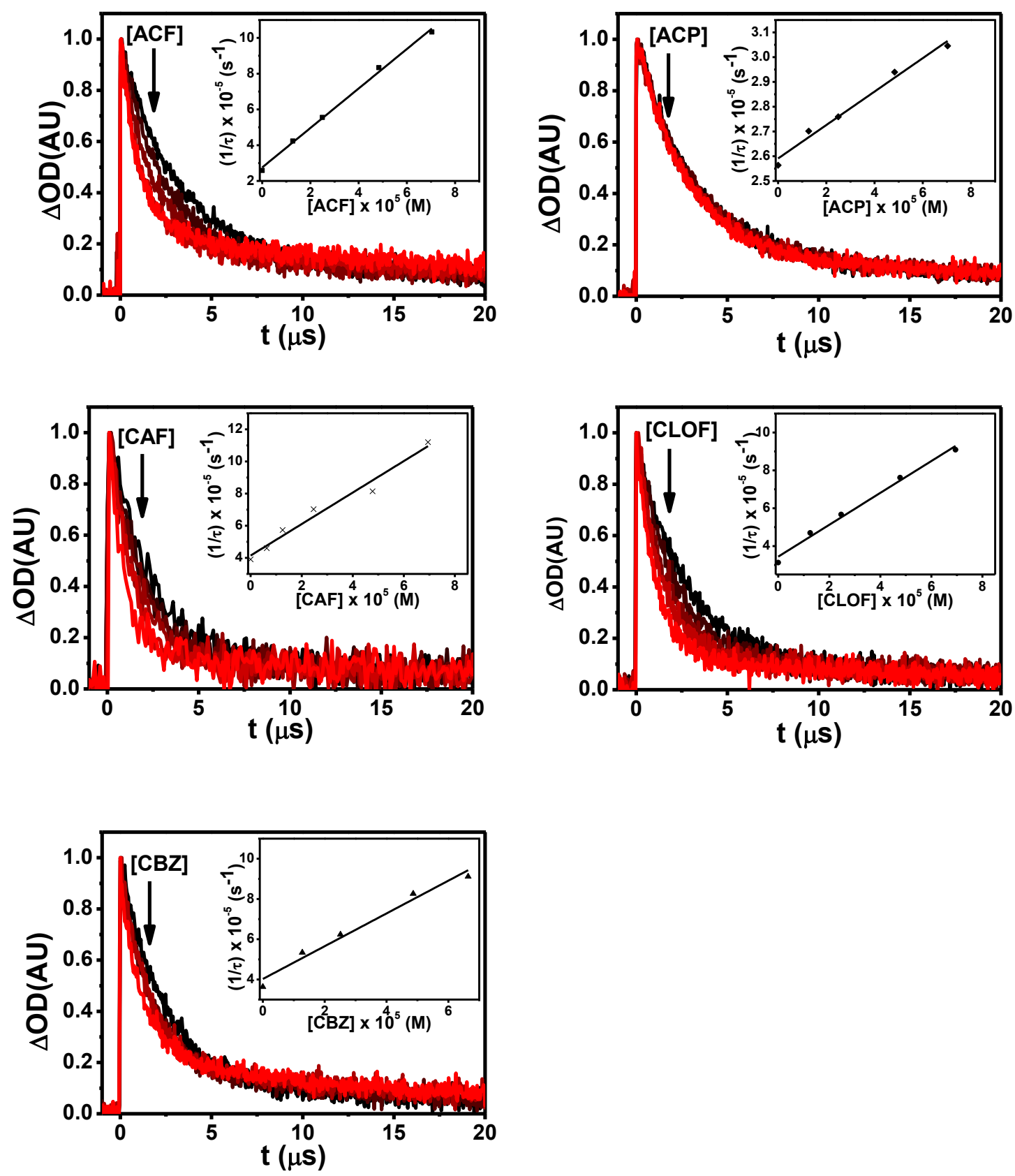

1

2 Fig. 5. Normalized kinetic traces obtained upon LFP excitation (355 nm) of deaerated 3 acetonitrile solutions $\left(7 \times 10^{-5} \mathrm{M}\right)$ of $\mathrm{TPTP}^{+}$upon increasing pollutant concentrations. 4 Insets: Corresponding Stern-Volmer plots.

\section{$5 \quad$ 3.3. Mechanistic proposal}

6 Quenching of the excited states of $\mathrm{TPTP}^{+}$could, in principle, be due to an energy transfer

7 mechanism or a photoinduced electron transfer one. The former was ruled out on the basis 
1 of the UV-visible spectra of the photocatalyst and pollutants (Fig.1 right and Fig. S1);

2 while $\mathrm{TPTP}^{+}$absorbs up to $450 \mathrm{~nm}$, the pollutants absorb at much shorter wavelength, all

3 below $320 \mathrm{~nm}$. Therefore, much more energetic excited states in the case of the pollutants

4 were inferred (both singlets and triplets). As a result, the energy transfer from $\mathrm{TPTP}^{+}$will

5 be thermodynamically disfavored in all cases. Moreover, using CAF as example, the

6 quenching of the triplet excited state of $\mathrm{TPTP}^{+}$was performed in an additional solvent of

7 lower relative permittivity to support the electron transfer process. Specifically,

8 tetrahydrofuran $(\varepsilon=7.58)$ was selected and compared to the result obtained in acetonitrile

$9 \quad(\varepsilon=35.94)$. The obtained quenching constants were $6.0 \times 10^{8} \mathrm{M}^{-1} \mathrm{~s}^{-1}$ and $9.8 \times 10^{9} \mathrm{M}^{-1} \mathrm{~s}^{-1}$

10 in tetrahydrofuran and acetonitrile, respectively; thus supporting the photoxidation

11 occurring through an electron transfer process (see Figure Sx in the Supplementary

12 Material). Therefore, the above detailed photophysical results allowed us to postulate the

13 following overall electron transfer mechanistic pathway to explain the observed

14 photodegradation of $\mathrm{ACF}, \mathrm{ACP}, \mathrm{CAF}, \mathrm{CLOF}$ and $\mathrm{CBZ}$ in the presence of $\mathrm{TPTP}^{+}(\mathrm{Scheme}$

15 1). In all cases quenching of the singlet and triplet excited states of $\mathrm{TPTP}^{+}$was observed,

16 while formation of complexes has only been demonstrated in the case of ACP.

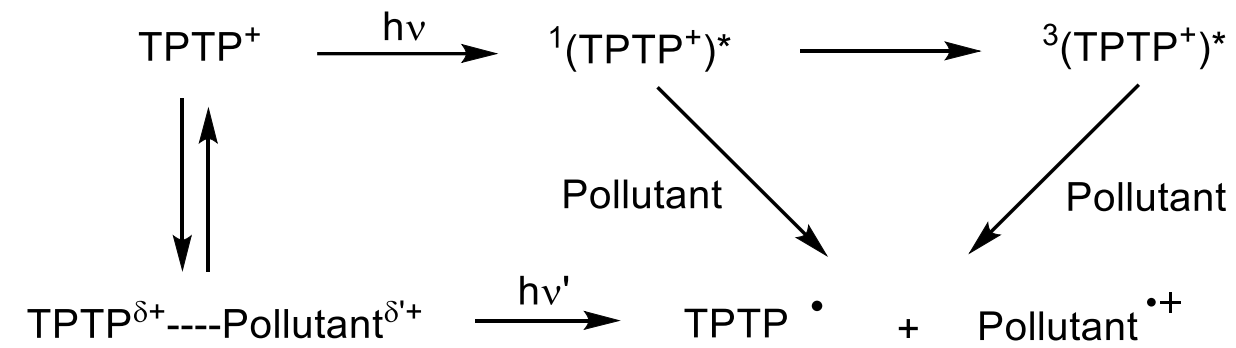

18 Scheme 1. Overall mechanistic pathways to explain photodegradation of pollutants by oxidative $\mathrm{e}^{-}$transfer to $\mathrm{TPTP}^{+}$. 
1 3.4. Relative contribution of the involved excited species at different pollutant

2

3

4

5

6

7 If part of the photocatalyst $(\mathrm{P})$ in its ground state is forming a complex with the pollutant 8

\section{concentrations}

The relative contribution of a photocatalyst-derived reactive species, singlet or triplet excited states, or photoactive ground-state complex can be evaluated on the basis of the following equations. In addition, the efficiency in the use of a photocatalyst to perform the photodegradation of the pollutants can be determined upon pollutant concentration.

(Q), the percentage of photocatalyst involved in it (for 1:1 stoichiometry) is shown in eq.4:

$$
K=\frac{\left[P^{\delta+} \ldots Q^{\delta \prime+}\right]}{\left([P]-\left[P^{\delta+} \ldots Q^{\delta \prime+}\right]\right)\left([Q]-\left[P^{\delta+} \ldots Q^{\delta \prime+}\right]\right)}(\text { eq. } 1)
$$

Assuming that:

$$
\left[P^{\delta+} \ldots Q^{\delta \prime+}\right] \ll[P] \text { and }\left[P^{\delta+} \ldots Q^{\delta^{\prime}+}\right] \ll[Q](\text { eq. } 2)
$$

$$
\left[P^{\delta+} \ldots Q^{\delta \prime+}\right] \cong K \times[P] \times[Q](\text { eq. } 3)
$$

$$
\left[P^{\delta+} \ldots Q^{\delta \prime+}\right](\%) \cong K \times[Q] \times 100(\text { eq. } 4)
$$

Therefore, the percentage of photocatalyst able to reach the singlet excited state comes from equation 5:

${ }^{1}(P)^{*}$ formation $(\%)=100-\left[P^{\delta+} \ldots Q^{\delta^{\prime}+}\right](\%) \approx 100-K \times Q \times 100=(1-K \times Q) \times 100($ eq. 5$)$

The processes that can occur to the photocatalyst from its singlet excited state include emission $\left(\Phi_{F} / \tau_{S}\right)$, intersystem crossing $\left(\Phi_{I S C} / \tau_{S}\right)$ and quenching by the pollutant $\left(k_{q s}[Q]\right)$, according to equation 6: 


$$
\sum \text { Processes } \text { from }^{1}(P)^{*}=\frac{\Phi_{F}}{\tau_{S}}+\frac{\Phi_{I S C}}{\tau_{S}}+k_{q S}[Q](\text { eq. 6) }
$$

2 In addition, the part of the photocatalyst that reaches the triplet excited state can be

3 deactivated following two additional pathways: intrinsic decay $\left(1 / \tau_{T}\right)$ and quenching by

4 the pollutant $\left(k_{q T}[Q]\right)$ as shown in equation 7 :

$$
\sum \text { Processes }_{\text {from }^{3}}(P)^{*}=\frac{1}{\tau_{T}}+k_{q T}[Q](\text { eq. 7) }
$$

6 Using the above defined equations, the percentage of photocatalyst that is used in the

7 quenching of the pollutants can be determined from eq. 8 (if it occurs from the singlet)

8 and eq. 11 (if it occurs from the triplet); therefore, the relative contribution of the singlet

9 and triplet excited states in the quenching can be compared among them and also

10 evaluated against the intrinsic decay of the triplet (eq. 12):

$$
\text { Quenching of }{ }^{1}(P)^{*}(\%)={ }^{1}(P)^{*} \text { formation }(\%) \times \frac{k_{q s}[Q]}{\frac{\Phi_{F}}{\tau_{S}}+\frac{\Phi_{I S C}}{\tau_{S}}+k_{q s}[Q]}(\text { eq. 8) }
$$

$$
\text { Quenching of }{ }^{3}(P)^{*}(\%)={ }^{3}(P)^{*} \text { formation }(\%) \times \frac{k_{q T}[Q]}{\frac{1}{\tau_{T}}+k_{q T}[Q]}(\text { eq. } 9)
$$

${ }^{3}(P)^{*}$ formation $(\%)={ }^{1}(P)^{*}$ formation $(\%) \times \frac{\frac{\Phi_{I S C}}{\tau_{S}}}{\frac{\Phi_{F}+\frac{\Phi_{I S C}}{\tau_{S}}+k_{q S}[Q]}{\tau_{S}}}($ eq. 10)

14 Quenching of ${ }^{3}(P)^{*}(\%)={ }^{1}(P)^{*}$ formation $(\%) \times \frac{\frac{\Phi_{I S C}}{\tau_{S}}}{\frac{\Phi_{F}}{\tau_{S}}+\frac{\Phi_{I S C}}{\tau_{S}}+k_{q S}[Q]} \times \frac{k_{q T}[Q]}{\frac{1}{\tau_{T}}+k_{q T}[Q]}$ (eq.11)

15 Deactivation of ${ }^{3}(P)^{*}(\%)={ }^{1}(P)^{*}$ formation $(\%) \times \frac{\frac{\Phi_{I S C}}{\tau_{S}}}{\frac{\Phi_{F}}{\tau_{S}}+\frac{\Phi_{I S C}}{\tau_{S}}+k_{q S}[Q]} \times \frac{\frac{1}{\tau_{T}}}{\frac{1}{\tau_{T}}+k_{q T}[Q]}($ eq. 12$)$

16 As it can be seen from the above equations, the relative contribution of the different 17 deactivation channels of the photocatalyst depends on its intrinsic properties, on the 
1 experimentally determined quenching constants and on the quencher (pollutant)

2 concentration.

3 In this particular example, only formation of photoactive ground-state complex, singlet

4 and triplet excited states are considered. Then, from the experimentally obtained

5 quenching rate constants for the pollutants (Table 1) and using the intrinsic data of the

6 photocatalyst (Fig. 1 middle), [8] the determined relative contribution of every pathway

7 is shown in Table 2.

8

9 Table 2. Relative contributions of the ground-state complex formation, singlet and triplet quenchings and intrinsic singlet and triplet deactivation in the photocatalytic degradation of the pollutants using TPTP ${ }^{+}$.

12

\begin{tabular}{|c|c|c|c|c|c|c|}
\hline $\begin{array}{l}{[\mathbf{Q}]} \\
(\mathbf{M})\end{array}$ & Pollutant & $\begin{array}{c}\text { Complex } \\
\text { formation } \\
(\%)\end{array}$ & $\begin{array}{c}\text { Quenching } \\
\text { of } \\
{ }^{1} \text { (TPTP)* } \\
(\%)\end{array}$ & $\begin{array}{c}\text { 1(TPTP)* } \\
\text { intrinsic } \\
\text { decay }(\%)\end{array}$ & $\begin{array}{c}\text { Quenching } \\
\text { of } \\
{ }^{3} \text { (TPTP)* } \\
(\%)\end{array}$ & $\begin{array}{c}\text { 3(TPTP)* } \\
\text { intrinsic } \\
\text { decay }(\%)\end{array}$ \\
\hline \multirow{5}{*}{$10^{-3}$} & ACF & - & 3.2 & 5.8 & 89.2 & 1.8 \\
\hline & ACP & 50.6 & 1.6 & 2.9 & 33.7 & 11.3 \\
\hline & CAF & - & 3.2 & 5.8 & 89.0 & 2.1 \\
\hline & CLOF & - & 3.2 & 5.8 & 88.6 & 2.5 \\
\hline & CBZ & - & 3.2 & 5.8 & 88.6 & 2.4 \\
\hline \multirow{5}{*}{$10^{-5}$} & ACF & - & $<0.1$ & 6.0 & 30.7 & 63.2 \\
\hline & $\mathrm{ACP}$ & 0.5 & $<0.1$ & 6.0 & 2.7 & 90.8 \\
\hline & CAF & - & $<0.1$ & 6.0 & 28.3 & 65.7 \\
\hline & CLOF & - & $<0.1$ & 6.0 & 24.8 & 69.2 \\
\hline & CBZ & - & $<0.1$ & 6.0 & 25.4 & 68.6 \\
\hline
\end{tabular}

14 As it can be seen from Table 2, when quenching of singlet and triplet occurs, the relative contribution of the singlet is negligible compared to that of the triplet, in agreement with the general fact that the shorter the lifetime of the excited species, the more difficult to be quenched. Therefore, since quenching of the triplet is more efficient than quenching of the singlet, we could state that the higher the intersystem crossing quantum yield, the better. In addition, the values obtained for the quenching constants of the triplet are in 
1 good agreement with the photodegradation extent (Fig. 3) except from the case of CLOF

2 in which oxidation is even faster than predicted by the photophysical experiments.

3 Moreover, regarding the efficiency of the photocatalyst versus pollutant concentration,

4 one can imagine how efficient the excited photocatalyst can be in the source of disposed

5 wastewater, when the concentration of the pollutants is still high (for instance in the order

6 of $\left.10^{-3} \mathrm{M}\right)$. This situation could be compared to another one in which the photocatalyst is

7 applied later on in the wastewater stream when the pollutants are much more diluted (for

8 instance $\left.10^{-5} \mathrm{M}\right)$. From the data shown in Table 2, as the pollutant concentration

9 decreases, the relative contribution of the excited species decreases in favor of the

10 intrinsic decay of the excited state. This means that the higher the concentration of the

11 pollutants, the more efficient the photocatalyst is. In other words, the energy employed in

12 activating the photocatalyst is better invested when the concentration of the pollutants is

13 still high.

\section{Conclusions}

16 The results obtained using $\mathrm{TPTP}^{+}$as proxy for the photocatalytic oxidation of pollutants,

17 allow stating that the ideal photocatalyst should be the one that offers the following features: i) it absorbs in the visible region; ii) its redox potential from the excited state is appropriate; iii) it has a high intersystem crossing quantum yield; and iv) its triplet lifetime is long enough. In addition, one can envisage two different scenarios to treat an industrial effluent: i) as soon as the wastewater is generated, when the concentration of the pollutants is the highest, or ii) conversely, when the effluent reaches an open area, thus, the concentration of the pollutant has decreased. In the former, the efficiency of a photocatalytic treatment will be the best; while in the latter, although the efficiency of the 
1 triplets acting as photocatalyst is low, natural sunlight could become an inexpensive 2 illumination source (Fig. 6).

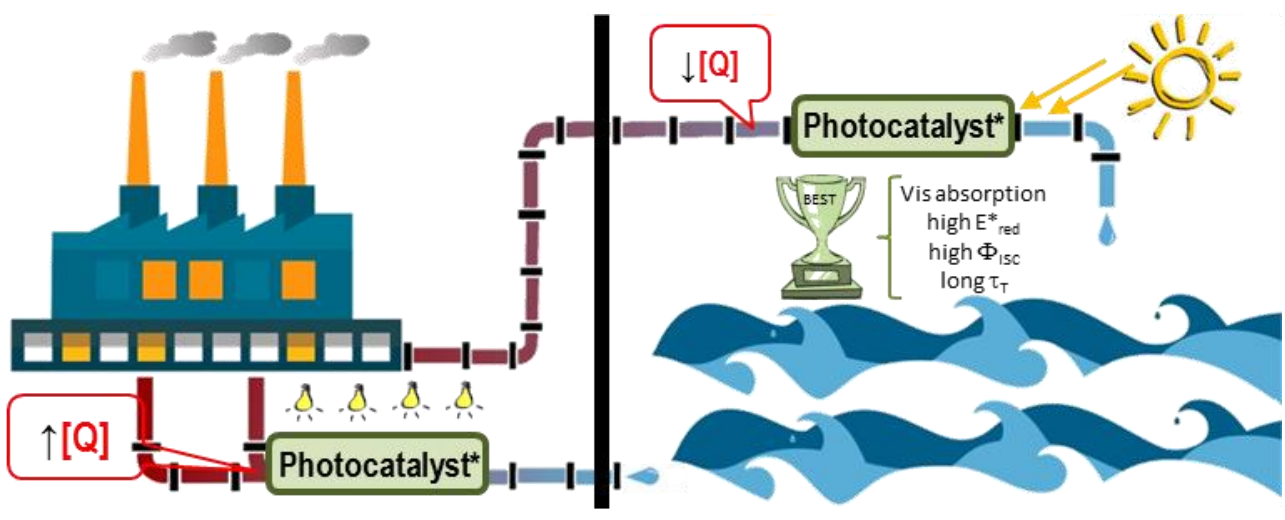

Fig. 6. Two different scenarios to treat wastewater effluents.

\section{Acknowledgements}

$9 \quad$ Financial support from Spanish Government (Grants SEV-2012-0267, CTQ2012-38754-

10 C03-02 and CTQ2012-38754-C03-03) and Generalitat Valenciana (Prometeo Program)

is gratefully acknowledged. We also thank support from VLC/Campus.

\section{References}

[1] S.K. Khetan, T.J. Collins, Human pharmaceuticals in the aquatic environment: A challenge to green chemistry, Chem. Rev., 107 (2007) 2319-2364.

[2] C. Tixier, H.P. Singer, S. Oellers, S.R. Müller, Occurrence and Fate of Carbamazepine, Clofibric Acid, Diclofenac, Ibuprofen, Ketoprofen, and Naproxen in Surface Waters, Environ. Sci. Technol., 37 (2003) 1061-1068.

[3] G.M. Rodriguez-Muñiz, J. Gomis, A. Arques, A.M. Amat, M.L. Marin, M.A. Miranda, Hydroxyl Radical as an Unlikely Key Intermediate in the Photodegradation of Emerging Pollutants, Photochem. Photobiol., 90 (2014) 1467-1469.

[4] J.V. Goldstone, B.M. Voelker, Chemistry of Superoxide Radical in Seawater: CDOM Associated Sink of Superoxide in Coastal Waters, Environ. Sci. Technol., 34 (2000) 1043-1048. 
[5] A. Paul, S. Hackbarth, R.D. Vogt, B. Roder, B.K. Burnison, C.E.W. Steinberg, Photogeneration of singlet oxygen by humic substances: comparison of humic substances of aquatic and terrestrial origin, Photochem. Photobiol. Sci., 3 (2004) 273-280.

[6] P.P. Vaughan, N.V. Blough, Photochemical formation of hydroxyl radical by constituents of natural waters, Environ. Sci. Technol., 32 (1998) 2947-2953.

[7] S. Canonica, Oxidation of Aquatic Organic Contaminants Induced by Excited Triplet States, Chimia, 61 (2007) 641-644.

[8] M.L. Marin, L. Santos-Juanes, A. Arques, A.M. Amat, M.A. Miranda, Organic Photocatalysts for the Oxidation of Pollutants and Model Compounds, Chem. Rev., 112 (2012) 1710-1750.

[9] M.A. Miranda, H. Garcia, 2,4,6-Triphenylpyrylium Tetrafluoroborate as an Electron-Transfer Photosensitizer, Chem. Rev., 94 (1994) 1063-1089.

[10] J. Gomis, A. Arques, A.M. Amat, M.L. Marin, M.A. Miranda, A mechanistic study on photocatalysis by thiapyrylium salts. Photodegradation of dimethoate, alachlor and pyrimethanil under simulated sunlight, Appl. Catal. B, 123 (2012) 208-213.

[11] R. Martinez-Haya, M.H. Barecka, P. Miro, M.L. Marin, M.A. Miranda, Photocatalytic Treatment of Cork Wastewater Pollutants. Degradation of Gallic Acid and Trichloroanisole using Triphenyl(thia)pyrylium salts, Appl. Catal. B, 179 (2015) 433-438.

[12] Y. Li, S.-M. Chen, The Electrochemical Properties of Acetaminophen on Bare Glassy Carbon Electrode, International Journal of Electrochemical Science, 7 (2012) 2175-2187.

[13] W.A. Arnold, One electron oxidation potential as a predictor of rate constants of Ncontaining compounds with carbonate radical and triplet excited state organic matter, Environmental Science-Processes \& Impacts, 16 (2014) 832-838.

[14] A. Ambrosi, R. Antiochia, L. Campanella, R. Dragone, I. Lavagnini, Electrochemical determination of pharmaceuticals in spiked water samples, J. Hazard. Mater., 122 (2005) 219225.

[15] X. Han, W. Hao, X.-Q. Zhu, V.D. Parker, A Thermodynamic and Kinetic Study of Hydride Transfer of a Caffeine Derivative, J. Org. Chem., 77 (2012) 6520-6529.

[16] M.A. Miranda, A.M. Amat, A. Arques, Stability and performance of silica gel-supported triphenylpyrylium cation as heterogeneous photocatalyst, Catal. Today, 76 (2002) 113-119.

[17] M.L. Marin, A. Miguel, L. Santos-Juanes, A. Arques, A.M. Amat, M.A. Miranda, Involvement of triplet excited states in the electron transfer photodegradation of cinnamic acids using pyrylium and thiapyrylium salts as photocatalysts, Photochem. Photobiol. Sci., 6 (2007) 848-852.

[18] M.L. Marin, V. Lhiaubet-Vallet, L. Santos-Juanes, J. Soler, J. Gomis, A. Argues, A.M. Amat, M.A. Miranda, A photophysical approach to investigate the photooxidation mechanism of pesticides: Hydroxyl radical versus electron transfer, Appl. Catal. B, 103 (2011) 48-53.

[19] P. Miro, A. Arques, A.M. Amat, M.L. Marin, M.A. Miranda, A mechanistic study on the oxidative photodegradation of 2,6-dichlorodiphenylamine-derived drugs: Photo-Fenton versus photocatalysis with a triphenylpyrylium salt, Appl. Catal. B, 140 (2013) 412-418.

[20] S.L. Murov, I. Carmichael, G.L. Hug, Handbook of Photochemistry, 2nd ed., Marcel Dekker, New York, 2009.

[21] P. Maccarthy, Simplified experimental route for obtaining jobs curves, Anal. Chem., 50 (1978) 2165-2165.

[22] C.Y. Huang, Determination of Binding Stoichiometry by the Continuous Variation Method - the Job Plot, Methods in Enzymology, 87 (1982) 509-525.

[23] H.A. Benesi, J.H. Hildebrand, A spectrophotometric investigation of the interaction of iodine with aromatic hydrocarbons, J. Am. Chem. Soc., 71 (1949) 2703-2707.

[24] S. Nigam, G. Durocher, Spectral and photophysical studies of inclusion complexes of some neutral $3 \mathrm{H}$-indoles and their cations and anions with beta-cyclodextrin, J. Phys. Chem., 100 (1996) 7135-7142. 